\title{
Broiler Management - The First 24 Hours 1
}

\section{G. D. Butcher, DVM, Ph.D., Amir H. Nilipour, Ph.D. ${ }^{2}$}

More than 30 billion broiler chicks are produced worldwide on an annual basis. Fifteen billion of these are produced in the Americas. Due to the poultry industry's tendency towards more intensive production practices and increased automation, the tender loving care once afforded to chickens in grow-out has been replaced with a mass production mentality. As a result, newly hatched chicks are often subjected to numerous stressors in the first 24 hours after hatching. These adverse effects during the critical early hours following hatch can result in an increased percentage of early mortality. These early stressors also influence final performance, resulting in declines in final body weights, increases in feed conversions and cost per pound of meat produced. Farm personal must understand that they have become the "adoptive parents" of these chicks. Without attention to details, successful and profitable grow-out is not realized.

\section{Biosecurity}

No health, no gain. The objective of any broiler farmer is to receive the highest quality chicks possible. Sick, stressed, underweight, dehydrated, or weak chicks will not perform to their genetic potential in a densely populated broiler house. Assuming the chicks arrive to the farm in good health, it is then essential to ensure that the broiler farm has been decontaminated as much as possible. This means that the farm has been completely washed and disinfected and that a minimal downtime has been scheduled before receiving the next flock. Healthy chicks can become infected and diseased soon after arrival to a contaminated, poorly sanitized farm. Successful producers recognize that losses due to disease outbreaks are greater under conditions of poor sanitation, as compared to houses that have been thoroughly cleaned and disinfected before chick placement. Following chick placement, everyone at the farm must adhere strictly to comprehensive biosecurity practices. Most importantly, it is essential to prevent entry of unauthorized or unnecessary visitors. If a farm needs to be visited, a complete change of clothing (coverall and boots) and/or taking real showers before entry is strongly recommended. Care must be exercised in visiting farms in the proper order, normally youngest to oldest. Common sense also dictates that suspect diseased farms be visited last. It is easier and less stressful for all to receive healthy chicks and keep them healthy during the production cycle. An intregal part of any biosecurity plan is to ensure that

1. This document is VM124, one of a series of the Veterinary Medicine-Large Animal Clinical Sciences Department, Florida Cooperative Extension Service, Institute of Food and Agricultural Sciences, University of Florida. Original publication date May 1, 2002. Visit the EDIS Web Site at http://edis.ifas.ufl.edu.

2. Gary D. Butcher, extension veterinarian, University of Florida College of Veterinary Medicine, IFAS, Gainesville, FL., Amir H. Nilipour, PhD, Director of Investigation and Quality Assurance, Grupo Melo, S.A., Panama, Republic of Panama; Richard D. Miles, Ph.D., Professor, Poultry Nutritionist, University of Florida, IFAS, Department of Dairy and Poultry Sciences, Gainesville, FL. 
the recently hatched chicks are properly vaccinated at the hatchery. Vaccines are intended to assist chicks in developing resistance against specific diseases, not to add another stress during the initial days of life. Vaccinate only with vaccines that are needed, and administer them as recommended by the manufacturer.

\section{The Most Crucial Part of a Chick's Life}

The first 24 hours of the chick's life are the most important. The farms must be ready and inspected one day prior to the chick's arrival. Following are some of the basic parameters that must be taken into consideration before and during the first hours of the chick's life to facilitate a good start and finish.

\section{Genetic Improvements}

In the past two decades, the age of processing a 4.4 pound broiler has dropped from 60 days to less than 40 days. This means that the first week of life of a modern, fast-growing broiler now accounts for about $20 \%$ of the broiler's life, compared with $10 \%$ just 20 years ago. This rapid growth rate puts even more demands on management during the first week of life, leaving the broiler grower with less time to correct to deficiencies. The performance lost due to improper management can not be compensated for, as there is no time.

\section{Air Quality}

After biosecurity, the next most important factor is to provide good quality, warm, fresh air that is rich in oxygen for the recently hatched chicks. The chick's trachea is normally irritated from being boxed and shipped in the chick trays, often for many hours. Chicks are often also exposed to formaldehyde gas and contaminated air during hatch. It is important to ensure that air quality is optimum for the chicks on arrival and that it does not contain unacceptable levels of carbon dioxide and ammonia. Excessive amounts of these irritants can cause depression, dehydration, emaciation and eventually death. Poor ventilation may result in carbon monoxide (CO) accumulation, reaching toxic levels. Toxicity causes an irreversible condition that cannot be corrected with additional ventilation. Maintaining acceptable air quality is an art, and can be achieved by manipulating the curtains, extractors, etc. The purpose is to provide fresh air to the chicks without chilling or drafting the chicks or wasting expensive heating fuel. The broiler farm supervisors must understand how to manage the farms to provide warm, fresh air at all times, irrespective of outside conditions.

\section{Brooding Temperature}

The broilers' production cycle is short. For approximately one-half of their life, broiler chicks have an immature thermo-regulatory system that cannot regulate internal body temperature when exposed to temperatures outside a relatively small range. Thus proper brooding is critical, and optimum growth during the first days of life will be dependent on the grower. Management practices should be modified depending on the actual climatic conditions and local geography. However, without exception all chicks must be provided environmental temperatures from $88^{\circ}-92^{\circ} \mathrm{F}$ for the first 24 hours. Experiments conducted by the authors (Table 1) have shown that when chicks were brooded with lower than suggested temperatures, depressed growth, higher feed conversion, increased morality, and an average 40 index points decline occurred.

Table 1. Effect of varying brooding temperatures on male and female broiler performance at 42 days of age.

\begin{tabular}{|c|c|c|c|}
\hline Parameters & $\mathbf{8 8}^{\circ}-\mathbf{9 0} \mathbf{}^{\circ} \mathbf{F}$ & Cool & Cold \\
\hline $\begin{array}{c}\text { Body weight in } \\
\text { grams at 7 DOA }\end{array}$ & 138.11 & 129.10 & 120.78 \\
\hline $\begin{array}{c}\text { Body weight in } \\
\text { grams }\end{array}$ & 2335.98 & 2298.47 & 2258.38 \\
\hline $\begin{array}{c}\text { Body weight in } \\
\text { pounds }\end{array}$ & 5.145 & 5.063 & 4.974 \\
\hline Conversion & 1.803 & 1.829 & 1.862 \\
\hline $\begin{array}{c}\text { Ave. daily weight } \\
\text { gain in grams }\end{array}$ & 55.62 & 54.73 & 53.77 \\
\hline \%Culls & 0.42 & 2.92 & 3.75 \\
\hline \% Ascites & 1.67 & 1.67 & 5.00 \\
\hline$\%$ Total Mortality & 2.92 & 5.83 & 8.33 \\
\hline Index 42 days & 299.42 & 281.72 & 264.68 \\
\hline $\begin{array}{c}\text { Increased cost } \\
\text { vs. control (cents) }\end{array}$ & 0.00 & 0.78 & 1.66 \\
\hline
\end{tabular}


The cost to produce a pound of meat using suboptimal brooding temperatures was increased 1.6 cents/pound. The percent mortality for the chicks brooded under suboptimal temperatures was more than $8 \%$, with $5 \%$ due to ascites that increased when using suboptimal brooding temperatures.

Before the chicks arrive, evaluate temperatures throughout the brooding area with a digital thermometer. Determine temperatures on litter surface and approximately $2 \mathrm{~cm}$. above the litter. This is where the chicks will be placed. After placing the chicks, monitor their behavior and spread pattern to determine if the temperature and ventilation are suitable. In reality, there is no need for sophisticated equipment. Simply observing the chicks closely enables one to determine if problems exist. The farm managers need to understand and recognize the behavior of content chicks versus stressed chicks.

\section{Water}

Chicks can be withheld water and feed for 100 hours or more, receiving total nutrients from their absorbed yolk sac residue. However, this does not suggest that feed and water intake should purposely be restricted. Ideally, the chicks should be placed at the farm and provided water and feed in less than 8 hours from time of hatch. Longer delays could lead to dehydration and chick weight shrinkage. If long delays are expected, there are commercial nutritive hydrants available that can be placed in the chick boxes while they are being transported to the farm. The water quality, purity, and temperature must be checked in advance. Contaminated water can spread disease and cause diarrhea, leading to dehydration and death in younger flocks. If the chicks have been in transport for a long period, providing water for the first 3 or 4 hours, and then providing feed is suggested. In other words, it is imperative that chicks be encouraged to consume water as soon as possible. Many managers add some sort of sweetener substance, like sugar to the water ( $4 \%$ solution) for the first few hours of life. The sugar helps to replenish the depleted energy in the chicks, and may stimulate the chicks to consume feed. The sweet water can also may loosen up the impacted intestine and prepare the gut linings for the incoming feed. After the addition of sugar, it is recommended to add a vitamin supplement to the water for the first three days of life, to boost the chicks' vitality. With the exception of water vaccination time, drinking water must be adequately chlorinated. The chlorine level at the drinker level should be 1PPM-nipple drinkers, 2PPM-plasson drinkers, and 3PPM-trough drinkers.

\section{The Chick's Microclimate}

The newly hatched chick's surroundings should be as close to ideal as possible. This environment should be compared with the microenvironment that is provided for recently born human babies. The area must be cozy, warm, and clean. It should be provided detailed attention 24 hours a day.

\section{Equipment Density}

Before the chicks arrive, the farm supervisor must ensure that the brooding area is completely ready and adequate for the number of chicks arriving. This includes having adequate floor space, feeder, space, drinker space, high quality and fresh litter material in the brooding area, etc. Besides being adequate in number, the proper distribution of feeders and drinkers is also critical. It makes little sense to receive high quality healthy chicks and then deprive them of feed and water due to lack of equipment like feeders and waterers.

\section{Litter Quality}

Close attention to litter conditions must be ongoing. Litter that is old, caked, wet or dusty must be replaced with high quality, fresh litter. In areas where litter cannot be changed after each broiler cycle due to costs for new litter, availability of new litter, or difficulty in disposing of used litter, the litter should be changed only where the chicks are to be brooded the first week, and other areas where litter is caked. If changing litter in the brooding area is not possible, newspapers can be placed for the first 24 hours in the brooding area. The objective is to reduce exposure of the baby chicks to high levels of contaminants for the first few hours while the immune system is still immature and the yolk stalk remnant may still be healing. Litter type, temperature, texture, and moisture content all could affect the ability of the newly hatched chick to survive and thrive in their new surroundings. Chicks 
can lose much of their core temperature through the skin of their legs in contact with the litter. Thus, bedding that has not been properly warmed before the chicks are placed can dramatically reduce chick survival. In places where there are cold temperatures, it is recommended to warm up the brooding area for at least 24 hours before the chicks arrive to ensure litter temperatures have also warmed. To evaluate the litter temperatures, a thermometer can be used, or more simply, determine the chick's leg temperature by touching it against your skin.

\section{Feed and Water}

Microclimate management also includes consideration of the availability of high quality feed and water. Water should be at ambient temperature and feed particle size optimum for the chicks. A newly hatched chick is $85 \%$ water. When $10 \%$ of this water is lost, it becomes a cull chick, and when there is $20 \%$ dehydration, the chick could die. It is important to hydrate the chick adequately and promptly. This will promote feed consumption and better body weights. If water and feed are consumed in sufficient amounts and correct brooding temperature and air quality are provided, a broiler chick should be able to quadruple the post-hatch body weight by seven days of age. To monitor if chicks are consuming adequate feed, it is recommended to select chicks and palpate their crops. The crops should be quite full. If the crop feels half empty or empty, there must be something wrong in the management, and the above-discussed points must be reviewed very carefully. It is never too late to act and make corrections, but a problem must be detected before it can be corrected.

\section{Conclusion}

Before chicks arrive, inspect the house closely to ensure proper setup. After a poor start, there is little time to compensate for the lost growth as a chick's life is only approximately 1000 hours. Thus, every hour represents $0.10 \%$ of the chick's life. In a 24-hour period, $2.4 \%$ performance can be lost. Many producers recognize that performance lost the first day or first week will be reflected in final performance results. 